\title{
At the frontier of the global battle against emerging infections: surveillance and management of avian influenza $A(H 7 N 9)$ in Guangdong Province, China
}

\author{
Michael A Stoto ${ }^{1}$, Min Kang ${ }^{2}$, Tie Song ${ }^{2}$, Jennifer Bouey³, Matthew R Boyce ${ }^{1}$, Rebecca Katz ${ }^{1}$ \\ ${ }^{1}$ Center for Global Health Science \& Security, Georgetown University, Washington, D.C., USA, 2 Guangdong Provincial Centers for Disease Control, \\ Guangdong, China, ${ }^{3}$ Department of International Health, School of Nursing and Health Studies, Georgetown University, Washington, D.C., USA \\ Keywords: global health
}

https://doi.org/10.29392/joghr.3.e2019018

\section{Journal of Global Health Reports}

Vol. 3, 2019

\begin{abstract}
Background
Guangdong, which stands at the frontier of emerging infections, has developed an innovative system approach to this threat. The province of 110 million inhabitants, a major hub for domestic and international trade, includes mega-cities side-by-side with small-scale agricultural areas in a region from which recent strains of influenza and other respiratory viruses have emerged. Guangdong residents consume chicken and purchase it at live poultry markets, which can accelerate the emergence of influenza strains and transmission to humans. We describe Guangdong's approach to surveillance and public health emergency response.
\end{abstract}

\section{Methods}

We use H7N9 as a case study to illustrate how Guangdong's system functions.

\begin{abstract}
Results
Guangdong’s approach includes five core elements - real-time surveillance, risk assessment, rapid response, active and accurate intervention, and multilateral communication. This requires partnerships among governmental agencies at all levels as well as healthcare professionals and residents. Risk management, for instance, involves not only provincial and local Centers for Disease Control, other government agencies, hospitals and clinics, and wholesale and live poultry markets. The implementation of Guangdong's risk management strategy depends, in part, on available resources and existing capacities. Guangzhou and a majority of Guangdong Province implement "control risk" level strategies. However, the city of Shenzhen (as well as neighboring Hong Kong), implement “eliminate risk.” level strategies.
\end{abstract}

\section{Conclusions}

Effective disease surveillance requires vertical and horizontal coordination among public health agencies. Similarly, disease prevention and control efforts also require partnerships with other governmental agencies at all levels, as well as with healthcare professionals and civil society. Guangdong Province has developed an approach for surveillance and control of H7N9 that may represent a robust and potentially scalable model for China and other nations.

Guangdong Province, China stands at the frontier of the global battle against emerging infections, especially avian influenza. The densely populated, subtropical province of 110 million inhabitants includes several mega-cities - such as Guangzhou and Shenzhen, with 12 and 11 million residents respectively ${ }^{1}$ - and is adjacent to the autonomous region of Hong Kong, which has a population of 7 million. ${ }^{2}$ These urban areas exist adjacent to more rural environments, but Guangdong is still the most urbanized province in China (estimated to be $60.6 \%$ urban in 2005). ${ }^{3}$ All this in a part of the world from which many recent respiratory diseases have emerged including strains of avian and human influenza, severe acute respiratory syndrome (SARS), and others. ${ }^{4}$

Within China, increasing per-capita income has resulted in increasing per-capita meat consumption, and poultry production and consumption are rapidly increasing. Guangdong residents consume more chicken than other areas of China and prefer to purchase poultry at "wet" (live poultry) markets that sell live and freshly slaughtered product. These markets provide conditions that can accelerate the emergence of avian influenza strains and their transmission 
to human populations and have been closely linked to the spillover of avian influenzas. 5,6

The province is also a major economic hub for domestic and international trade. The cities of Guangzhou and Zhanjiang hold thousands of companies and are stops on the Belt and Road Initiative, which links China to 76 countries in Asia, Africa, and Europe, and approximately 60 percent of the world's population. ${ }^{7}$ And as a major manufacturing region that serves as the hub of the Maritime Silk Road ${ }^{8}$, Guangdong houses substantial amounts of international immigrants and travelers.

Because of its geographical location, population and epidemiology, and role in China's economic development, Guangdong Province requires a robust public health system to mitigate the risks posed by emerging infectious diseases. Accordingly, Guangdong has developed a provincial-level public health system approach composed of five core elements: (i) real-time surveillance, (ii) risk assessment, (iii) rapid response, (iv) active and accurate intervention, and (v) multilateral communication. Recognizing that other areas of China, as well as other countries, may wish to consider this system as a model, this analysis provides a detailed review of the public health structures, strategies, and policies in the province. Herein, we describe the Guangdong Province's approach to infectious disease surveillance and public health emergency response and use avian influenza $\mathrm{A}(\mathrm{H} 7 \mathrm{~N} 9)$ as an example to illustrate how these systems function.

\section{GUANGDONG'S APPROACH TO DISEASE SURVEILLANCE AND EMERGENCY RESPONSE}

Guangdong's approach to infectious disease surveillance and public health emergency response is composed of five core elements - real-time surveillance, risk assessment, rapid response, active and accurate intervention, and multilateral communication. The implementation of this strategy and Guangdong's public health system depend on a tiered system of Centers for Disease Control (CDCs) at the national, provincial, district, and community level. At each level, these CDCs work with a hierarchy of public health clinics, infectious disease hospitals, and other governmental agencies, some of which also have a tiered structure ${ }^{9}$, including those dealing with food and agriculture, creating a complex, and interconnected public health network (Figure 1).

\section{SURVEILLANCE}

The province's approach to surveillance is based on adapting national policies to local circumstances. The approach includes real-time case-based surveillance, environmental surveillance, and event-based media surveillance. Information from these various surveillance systems, as well as expert reports and assessments, is available on a web portal.

Community-level CDCs conduct comprehensive realtime surveillance in collaboration with hospitals, public health departments, and other institutions. CDC workers and healthcare workers at local public health clinics and hospitals collect infectious disease case reports and upload

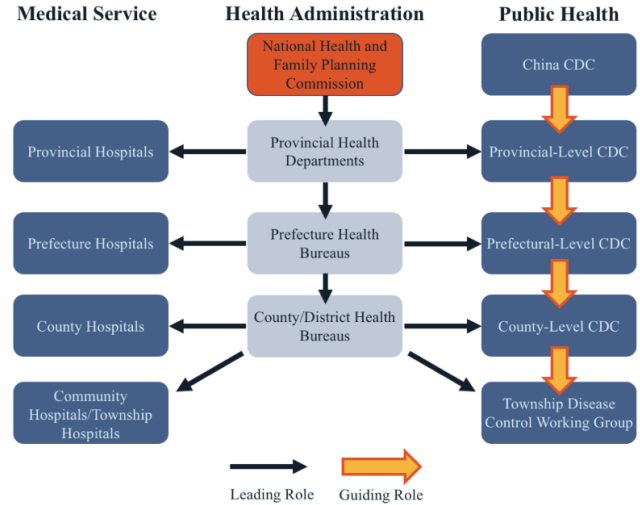

\section{Figure 1}

Hierarchal structure of the Chinese public health system including the centers for disease control (CDCs), hospitals, public health departments, and other institutions.

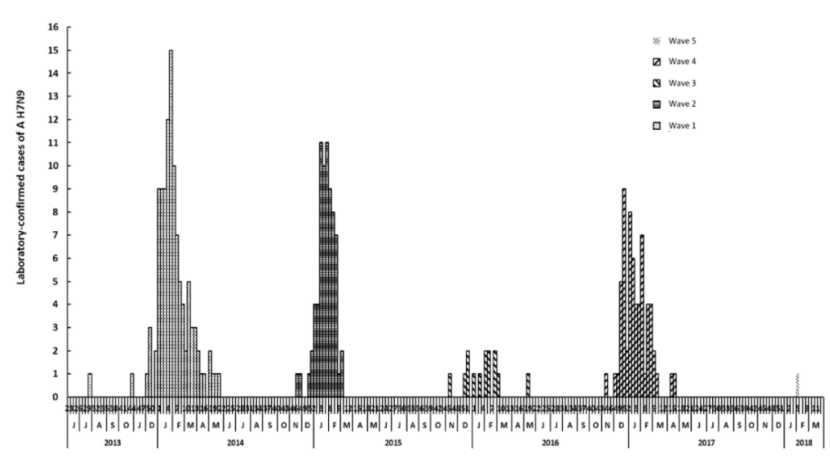

Figure 2

Temporal pattern of confirmed human influenza A(H7N9) infections in Guangdong Province (August 2013-March 2018).

them to a web-based, database, the China Information System for Disease Control and Prevention (CISDCP). ${ }^{9}$ This database serves to standardize reporting and affords for morbidity and mortality data to be readily accessible within the healthcare system via the internet. ${ }^{9}$ Figure 2 displays the results of this case surveillance for confirmed human influenza A(H7N9) infections in Guangdong Province from August 2013 through March 2018. The data demonstrate five distinct waves, of variable size and duration, since 2013, and no substantial outbreak since 2017.

The CDCs conduct environmental surveillance at poultry farms, wet markets, and other locations at an elevated risk for avian influenza. CDC workers also monitor high-risk groups such as those who work at these locations. The environmental surveillance system provides regular epidemiology reports documenting the number, demographic characteristics, geographical location of cases, and the case-fatality rate of avian influenza infections. The provincial-level CDC also has an event-based surveillance task force that monitors a variety of media and social media outlets (email, WeChat, MMS, etc.). Integrating information from these and other sources in real-time allows for 
Guangzhou CDC to rapidly detect, report, confirm, and assess events that may constitute a public health emergency.

\section{RISK ASSESSMENT}

Building on the case and laboratory network used for realtime surveillance, the Guangdong CDC conducts risk assessments for a variety of pathogens - including seasonal \& novel influenzas, norovirus, mumps, hand foot \& mouth disease, dengue, and other notifiable diseases (e.g., Ebola) on a variety of timescales. These assessments are prepared on a regular schedule for key pathogens, and rapid, in-depth risk assessments are conducted for emergencies and other situations of concern.

\section{RAPID RESPONSE}

The surveillance data and risk assessments enable a rapid and effective response to manage disease outbreaks. One component is well-staffed rapid response teams at the provincial, district, and in some cases municipal levels that prioritize disease control once an acute outbreak has been confirmed.

Using H7N9 avian influenza as an example, Table 1 illustrates Guangdong's hierarchal approach to epidemic prevention and control and risk management strategy. The lowest level, "contain risk," includes routine prevention strategies such as strengthening surveillance systems and health education campaigns as well as improving the diagnosis and treatment of human cases. The focus is on reducing exposure by raising public awareness, but the outcome is likely to result in sporadic cases at multiple locations and widespread viral contamination.

The "mitigate risk" level adds environmental controls such as reconditioning live poultry markets and the implementation of the "1-1-1-0" Policy at poultry markets. This policy seeks to reduce the risk of human infection with avian influenzas by mandating one market disinfection per day, one thorough market cleaning per week, one market closure day per month, and zero (i.e., no) live poultry kept at markets overnight. The "mitigate risk" level also adds the immediate closure and disinfectant actions for markets where there are potential outbreaks. This level involves moderate costs for government and industry and is suitable for immediate implementation as a short-term goal. The cumulative outcomes of this level are effectively reducing the risk of infection among rural populations and sporadic cases in multiple locations.

The "control risk" level adds disinfection of poultry cages and transportation vehicles, strengthening management of live poultry wholesale markets, using a designated slaughterhouse, and temporary closure of all regional poultry markets. This level involves high costs for government and industry and is suitable as a short or intermediate goal. This approach should effectively eliminate the risk of urban population's exposure to the pathogen, but there still might be sporadic cases in villages and more rural areas.

The highest level, "eliminate risk," includes steps to strengthen the management of poultry farms, centralize slaughterhouses and markets, as well as closing live poultry markets and relying on refrigerated fresh poultry products.
This level has a considerable short-term impact on the poultry farming industry, requires changes in consumer behavior, and entails very high costs for government and industry, so is only suitable as a long-term goal. This approach effectively protects all populations and is expected to result in zero to few cases.

The implementation of Guangdong's risk management strategy depends, in part, on available resources and existing capacities. Guangzhou and a majority of Guangdong Province implement "control risk" level strategies. However, the city of Shenzhen (as well as neighboring Hong Kong), implement “eliminate risk" level strategies.

\section{ACTIVE AND ACCURATE INTERVENTION}

The Guangdong CDC's risk assessments provide a foundation for active interventions to manage disease outbreak. For example, in 2015, spatial phylogenetic analysis of viral samples indicated that a third-wave of H7N9 outbreaks in central Guangdong likely resulted from local virus persistence rather than reintroduction from another location. ${ }^{10}$ This demonstrated the persisting challenges to completely halt H7N9 virus persistence and dissemination with live poultry market interventions. ${ }^{10}$ This highlights the need for new, active interventions that rely on novel technologies and methods, enhanced capacities, and innovative prevention and control models.

\section{MULTILATERAL COMMUNICATION}

Multilateral communication is central to the success of all the other elements of Guangdong's strategy. Within China, CISDCP acts as the main vehicle for domestic data sharing. However, the Guangdong CDC is also part of several other domestic networks existing within China such as the National Acute Infectious Diseases Prevention and Control Public Health Emergency Response Team and PulseNet China.

International data-sharing is achieved through the Global Public Health Intelligence Network (GPHIN) and the Global Outbreak Alert and Response Network Member (GOARN). These networks search global media sources to identify information about disease outbreaks and ensure that technical expertise and skills are where they are most required. The Guangdong CDC also collaborates with neighboring Hong Kong and Macau by sharing monthly surveillance reports and disease specific reports. Provincial-level public health authorities also participate in an annual meeting that acts to facilitate regional discussion and collaboration around potential infectious disease threats and intervention methods.

\section{DISCUSSION}

Realizing the threats posed by emerging infectious diseases, Guangdong Province has developed an approach for surveillance and control of threats such as H7N9 influenza. This strategy represents a robust and potentially scalable model for other parts of China and other nations, especially in Southeast Asia. Additional research investigating questions regarding governance strategies for emerging infec- 
Table 1. Guangdong Province Human Infection with Avian Influenza A (H7N9) Epidemic Prevention and Control and Risk Management Strategy

\begin{tabular}{|c|c|c|c|}
\hline $\begin{array}{l}\text { Management } \\
\text { level }\end{array}$ & Intervention strategies & $\begin{array}{l}\text { Estimated } \\
\text { intervention costs }\end{array}$ & Expected outcomes \\
\hline \multirow[t]{5}{*}{$\begin{array}{l}\text { I. Eliminate } \\
\text { risk }\end{array}$} & $\begin{array}{l}\text { Centralize slaughterhouses and market refrigerated } \\
\text { meat only }\end{array}$ & $\begin{array}{l}\text { Very high costs for } \\
\text { government and } \\
\text { industry }\end{array}$ & Few to zero cases \\
\hline & $\begin{array}{l}\text { Maintain cold-chain from processing center to } \\
\text { wholesale market }\end{array}$ & $\begin{array}{l}\text { Considerable short- } \\
\text { term impact on poultry } \\
\text { farming industry }\end{array}$ & Protect all populations \\
\hline & Close live poultry markets in the cities and rural areas & $\begin{array}{l}\text { Requires consumers to } \\
\text { change behavior }\end{array}$ & \\
\hline & $\begin{array}{l}\text { Strengthen live poultry wholesale markets } \\
\text { management }\end{array}$ & $\begin{array}{l}\text { Suitable as a long-term } \\
\text { goal }\end{array}$ & \\
\hline & Strengthen poultry farms management & & \\
\hline \multirow[t]{5}{*}{$\begin{array}{l}\text { II. Control } \\
\text { risk }\end{array}$} & $\begin{array}{l}\text { Recondition poultry markets; strengthen poultry } \\
\text { market management for different poultry types and } \\
\text { areas; have a designated slaughterhouse }\end{array}$ & $\begin{array}{l}\text { High costs to } \\
\text { government and } \\
\text { industry }\end{array}$ & $\begin{array}{l}\text { Sporadic cases in } \\
\text { limited areas }\end{array}$ \\
\hline & Zero live poultry in markets overnight; disinfect cages & $\begin{array}{l}\text { Suitable as a as a short } \\
\text { or intermediate goal } \\
\text { with gradual } \\
\text { implementation }\end{array}$ & $\begin{array}{l}\text { Eliminate the risk of } \\
\text { exposure to the } \\
\text { pathogen in urban } \\
\text { populations }\end{array}$ \\
\hline & $\begin{array}{l}\text { Strict implementation of 1-1-1-0 Policy at the live } \\
\text { poultry market; reinforce the routine market closed } \\
\text { day policy }\end{array}$ & & \\
\hline & $\begin{array}{l}\text { Strengthen the management of the wholesale } \\
\text { markets for the three types of poultry; disinfect } \\
\text { transportation vehicles }\end{array}$ & & \\
\hline & $\begin{array}{l}\text { Close local markets that have potential for viral } \\
\text { infections or human cases; extend market closure } \\
\text { time, disinfect facilities immediately; consider } \\
\text { temporally closures of all regional live poultry } \\
\text { markets }\end{array}$ & & \\
\hline \multirow[t]{2}{*}{$\begin{array}{l}\text { III. Mitigate } \\
\text { risk }\end{array}$} & $\begin{array}{l}\text { Recondition live poultry markets; guarantee no } \\
\text { overlapping areas for slaughter and market }\end{array}$ & $\begin{array}{l}\text { Moderate costs to } \\
\text { government and } \\
\text { industry }\end{array}$ & $\begin{array}{l}\text { Sporadic cases in } \\
\text { multiple areas }\end{array}$ \\
\hline & $\begin{array}{l}\text { Close local markets that have potential for viral } \\
\text { infections or human cases; extend market closure } \\
\text { time, disinfect facilities immediately; consider } \\
\text { temporally closures of all regional live poultry } \\
\text { markets }\end{array}$ & $\begin{array}{l}\text { Suitable for immediate } \\
\text { implementation as a } \\
\text { short-term goal }\end{array}$ & $\begin{array}{l}\text { Reduce the risk of } \\
\text { contracting the disease } \\
\text { among rural } \\
\text { populations }\end{array}$ \\
\hline \multirow[t]{3}{*}{$\begin{array}{l}\text { IV. Contain } \\
\text { risk }\end{array}$} & Strengthen health education campaigns and activities & $\begin{array}{l}\text { Efforts focus on reduce } \\
\text { exposure by raising } \\
\text { public awareness and } \\
\text { disease prevention } \\
\text { knowledge }\end{array}$ & $\begin{array}{l}\text { Sporadic cases } \\
\text { reported constantly in } \\
\text { multiple locations }\end{array}$ \\
\hline & Strengthen infectious disease surveillance systems & & $\begin{array}{l}\text { Viral contamination is } \\
\text { widespread at markets } \\
\text { with year-round or } \\
\text { multi-year risks for } \\
\text { new cases }\end{array}$ \\
\hline & Improve influenza diagnosis and treatment & & \\
\hline
\end{tabular}

tious diseases should be encouraged by national governments, institutions, and donors to determine if the provincial strategies represent valid, evidence-based approaches that could be adopted in other environments.

A strength of the surveillance system is the real-time reporting of data. From 1985-2003, the Chinese surveillance system relied on digital, aggregate monthly reports [9). However, the 2003 SARS epidemic exposed key gaps in this approach and precipitated the Chinese government updating its surveillance systems to take advantage of mod- ern technologies. Although the approaches used in China depend on reliable internet access and other information, technology and communication capacities, which ultimately may limit the scalability of the approach in some regions, the ability to rapidly share information in a standardized way represents a strength of the model used in Guangdong Province.

Effective disease surveillance requires vertical and horizontal coordination among public health agencies. Acknowledging this, and as described in Figure 1, the vertical 
components of the strategy establish clear lines of authority, which are necessary for effectively responding to infectious outbreaks. The strategy's horizontal components encourage collaborations between local level healthcare workers, their CDC counterparts, and other health bureau personnel. This creates a network of actors that increases the geographic reach of surveillance activities, empowers lower-level workers, and promotes system transparency. Guangdong CDC is a member of GOARN and can receive announcements from the network, but reports on outbreaks through the Chinese CDC. The strategy also promotes partnerships with Hong Kong and Macau and sends and receives monthly epidemic alerts and special emerging epidemic reports to both, helping to alert other regional and global partners of potential emerging health risks.

Disease prevention and control efforts also require partnerships with other governmental agencies at all levels, as well as with healthcare professionals and civil society (Figure 3). For instance, in the risk management phase, the CDCs, Food and Drug Administration (FDA), agriculture department, hospitals and clinics, and wholesale and live poultry markets all have responsibilities. The strategy also recognizes the responsibilities of individuals, whether they be the staff at poultry markets, at the CDCs, or at hospitals and clinics, or regular citizens. To facilitate inter-agency communication, the provincial government routinely initiates meetings with the China FDA and agricultural department and business associations at the request of the Guangzhou CDC. There was also extensive inter-agency collaboration with Customs, police, and the CDC during the Ebola pandemic. The relationships among these agencies that were developed for H7N9 and other avian influenzas, especially the ability to coordinate within the government and communicate with international partners, proved critical in the response to a recent Middle East respiratory syndrome (MERS) case in Guangdong. ${ }^{11}$

Given the complexity of the Chinese public health system, and the necessity of coordinating with the autonomous regions of Hong Kong and Macau, the development of a multisectoral management plan for H7N9 is a major accomplishment that might serve as a model for other areas, in China and other countries, both in the region and beyond. However, there are challenges in implementing any plan. In particular, the discrepancy between the "eliminate risk" posture in Shenzhen and the "control risk" level management level in Guangzhou and most of Guangdong Province deserves attention. In part, this is a matter of local culture and economic development. Shenzhen is a newly developed city, with more highly educated residents, many from outside Guangzhou. As a result, live poultry is as integral to local cuisine, and there are fewer live poultry mar-

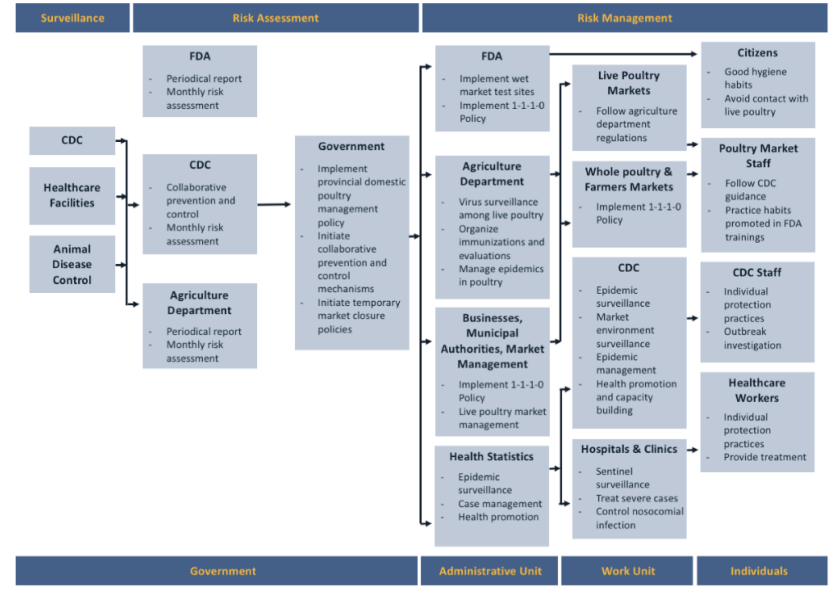

\section{Figure 3}

Risk management and prevention and control flow chart for avian influenza (H7N9, H5N6, H9N2), Guangdong Province. The bar at the top indicates the response phase: surveillance, risk assessment, and risk management. The bottom bar represents the level responsibility: government, administrative unit, work unit, and individuals.

kets, making the goal of "eliminating risk" more feasible. As noted in Lawton Burns' analysis of China's healthcare system and reform, ${ }^{12}$ financial constraints also matter to implementing healthcare strategies. While strategies and plans are developed or guided by the national-level CDC, the costs of surveillance, risk assessment, and risk management - including the social costs of intervention - are borne by local governments, where financial resources subject to greater heterogeneity and less predictable.

\section{CONCLUSION}

Successful disease surveillance and prevention and control strategies often require coordination and partnerships at different levels and across sectors. The strategies used by Guangdong Province for H7N9 may represent a useful model for others seeking a robust approach for disease surveillance.

\section{CORRESPONDENCE TO:}

Tie Song, MD

160 Panyu District

Guangzhou

Guangdong Province

P.R. China 511430

tsong@cdcp.org.cn 


\section{REFERENCES}

1. United Nations Population Division. World Urbanization Prospects 2018. Accessed January 30, 2019. https://population.un.org/wup/Download/

2. Government of the Hong Kong Special Administrative Region, Census and Statistics Department. Hong Kong Statistics - Population. Accessed January 30, 2019. https://www.censtatd.go v.hk/hkstat/sub/so20.jsp

3. Yeung J. Guangdong is most urbanized province, says report. China Daily. Published online May 12, 2007. http://www.chinadaily.com.cn/china/2007-05/1 2/content_870964.htm

4. Monagin C, Paccha B, Liang N, et al. Serologic and behavioral risk survey of workers with wildlife contact in China. PLoS ONE. 2018;13(4):e0194647. doi:10.137 1/journal.pone.0194647

5. Yu H, Cowling BJ, Feng L, et al. Human infection with avian influenza A H7N9 virus: an assessment of clinical severity. Lancet. 2013;382(9887):138-145. do i:10.1016/s0140-6736(13)61207-6

6. Gilbert M, Golding N, Zhou H, et al. Predicting the risk of avian influenza A H7N9 infection in livepoultry markets across Asia. Nat Commun. 2014;5(1). doi:10.1038/ncomms5116
7. Holmes F, Great Speculations Group. China's Belt and Road Initiave Opens Up Unprecedented Opportunities. Forbes. Published online September 4 2018. https://www.forbes.com/sites/greatspeculation s/2018/09/04/chinas-belt-and-road-initiative-opensup-unprecedented-opportunities/\#6bdde0413e9a

8. Tang K, Li Z, Li W, Chen L. China's Silk Road and global health. Lancet. 2017;390(10112):2595-2601. do $\mathrm{i}: 10.1016 / \mathrm{s} 0140-6736(17) 32898-2$

9. Wang L, Wang Y, Yang G, Ma J, Wang L, Qi X. China Information System for Disease Control and Prevention (CISDCP. Accessed January 30, 2019. htt p://pacifichealthsummit.org/downloads/HITCaseStud ies/Functional/CISDCP.pdf

10. Wu J, Lu J, Faria NR, et al. Effect of live poultry market interventions on Influenza A(H7N9) virus, Guangdong, China. Emerg Infect Dis. 2016;22(12):2104-2112. doi:10.3201/eid2212.160450

11. Song T, Kang M, Zhang Y, Liang L, Lin H. Elements of successful management of an imported Middle East respiratory syndrome case in Guangdong, China. Western Pac Surveill Response J. 2015;6(4):33-34. doi:10.5365/wpsar.2015.6.4.001

12. Burns LR, Liu GG, eds. China's Healthcare System and Reform. Cambridge University Press; 2017. 